OUR ASTRONOMICAL COLUMN.

The Eclipsing Binary RX Herculis.-An extended series of observations of photographic magnitudes of this variable has lately been made and discussed by R. H. Baker and Edith E. Cummings (Laws Obs. Bull., No. 25). The observations were made by the extra-focal method and, in combination with the spectroscopic evidence, lead to the following conclusions :-The two stars are slightly ellipsoidal, and each has a radius about one and a half times that of the sun. The mass of each star is a little less than that of the sun, and the density is about one-fourth of the sun's density. The star eclipsed at principal conjunction is of magnitude 7.96 , and is brighter by 0.12 magnitude than its companion; its surface brightness, mass, and density are greater than those of the fainter star by 12,6 , and 9 per cent. respectively, and it is of slightly earlier spectral class (A). The distance between the centres of the two stars is about five times the radius of either star, or about $5,280,000 \mathrm{~km}$. At conjunction 70 per cent. of the disc of one star is eclipsed by the other. The period is 1.7785740 days (Shapley), and the semi-duration of eclipse $2 \mathrm{~h} .53 \mathrm{~m}$. The photographic magnitude of the system is $7 \cdot 264$, and the magnitudes at primary and secondary minima 7.84 and 7.7 I respectively. Outside eclipse the intensities generally increase towards secondary minimum, showing that the light of the star eclipsed at this time is augmented by radiation of its brighter companion.

Spectroscopic Resolving Power.-The resolving power of a spectroscope is limited by the diffractional broadening of the geometrical images of the slit, and, following Lord Rayleigh, the limit of resolution usually adopted is determined by the condition that the maximum of the central band corresponding to one of the lines should fall on the minimum of that of the second line. Under these conditions, for two lines of equal intensity, the intensity at the centre of the combined bands is 0.81 of that of the maxima. An experimental investigation made by C. M. Sparrow at the University of Virginia (Astrophysical Journal, vol. xliv., p. 76) has led to the result that the limit of resolution is given by the "undulation condition "that is, by the condition that the central minimum shall just disappear. The theoretical resolving power thus derived is about 26 per cent. greater than that given by the Rayleigh criterion. Among other matters of interest, a simple approximate formula is given for the resolving power of the Fabry and Perot interferometer.

The Minimum Radiation Visually Perceptible.Adopting the light from a 6 th magnitude star as the smallest amount perceptible, Dr. H. E. Ives has made an interesting calculation of the corresponding least quantity of radiant energy capable of exciting the sensation of light (Astrophysical Journal, vol. xliv., p. I24). Taking Russell's estimate that a candle at one metre distance is of stellar magnitude $-14 \cdot 18$, it is easily deduced that the brightness of a 6 th magnitude star is $0.849 \times 10^{-8}$ of this. Since a metre-candle is equivalent to $\mathrm{x} .59$ ergs per sec. per sq. cm., it follows that the least power corresponding to illumination from a light-source of the above brightness is $1.35 \times 10^{-8} \mathrm{ergs}$ per sec. per sq. cm. Assuming $6 \mathrm{~mm}$. as the diameter of the pupil, the radiation entering the eye from a light-source of maximum efficiency of the brightness of a 6 th magnitude star would be $0.38 \times 10^{-8}$ ergs per sec. On the assumptions made, this is the smallest amount of radiation perceivable by the eye, but it is important to note that the figures given only apply to radiation from a distant point-source, such as a star. At this rate of energy-reception the eye would receive through the pupil the elementary energy-quantum, in one-thousandth of a second.

NO. 2455, VOL. 98]

\section{METEOROLOGY IN WAR.}

ONG before the outbreak of the world conflagration of the past two years war and the weather was a subject which captivated many minds, mainly of non-scientific or semi-scientific people who were prepared to accept as proof the most superficial circumstances which seemed to substantiate any popular belief. Even during the progress of the present war there have been many discussions in the Press and before societies in this and in other countries which have had for their object the perpetuation of the old belief that gun-firing causes rain, though round Shoeburyness, our great gun-firing station, less rain falls than in any other part of the British Isles! These quasilearned discussions have been of no assistance to the fighting forces on sea or land.

Scientific investigators, however, have not been idle, though little or nothing of their activities is known outside official circles. The meteorological establishments of the various countries involved in the great war have been doing their utmost to utilise the now very greatly increased knowledge of the physics of the atmosphere for the immediate benefit of the armies. Perhaps, at first sight, it would be natural to infer that meteorologists can go no further than prepare, on the lines familiar to us during the past half-century, predictions of the weather changes likely to take place within the coming twenty-four hours. But the matter has got far beyond this. As is stated in the eleventh annual report of the Meteorological Committee for the year ended March $3 \mathrm{I}$ last, just issued (Cd. $838 \mathrm{I}$, price Id.) :- "The variety of ways in which the weather affects warlike operations in all parts of the world has become very apparent from the diversity of the information which the Office is called upon to supply at short notice. The results of meteorological inquiries initiated in what appeared to be the remote interest of the theory of the circulation of the atmosphere have turned out to have important practical bearings.'

Both for naval and military operations accurate forecasts have been greatly enhanced in value, yet probably they are not more important than other tasks now undertaken by the meteorologists-for example, the behaviour of the upper atmosphere for the information of the flying services, and the condition of the surface atmosphere and its relation to gun-sighting and range-finding. According to the official report referred to above a separate unit of the Royal Engineers was created for a meteorological field service, that with the Expeditionary Force in France being under the command of Major Gold, one of the Meteorological Office superintendents, and that in the eastern Mediterranean under Capt. Wedderburn, honorary secretary of the Scottish Meteorological Society, assisted by Lieut. Kidson, of Canterbury College, New Zealand, and magnetician in the service of the Carnegie Institution of Washington. In view of the importance of an adequate knowledge of the weather to the proper conduct of naval and military operations in the Mediterranean generally, Major Lyons, R.E., formerly Director-General of the Egyptian Survey Department, was appointed to take charge of this section. Further, the importance of co-ordinating the experience of flying officers with the work of the Office and observatories in order to obtain more effective knowledge of the structure of the atmosphere has led to the appointment of Major G. I. Taylor, Schuster reader in meteorology, to the professorship of meteorology to the Royal Flying Corps.

That the responsible authorities appreciate the work performed by the meteorological services is evidenced by the Distinguished Service Order conferred on Major Gold, and the inclusion of some of his assistants in the Commander-in-Chief's despatches; while the 
Meteorological Office has received the special thanks of the Admiralty for its services in the Mediterranean. The world at large has been unaware of these manifold activities, imagining that the Meteorological Office practically ceased to exist when the daily forecasts in the newspapers came to an end. Yet during its silence the department has been worked far harder than ever before, and it was in recognition of the success of the service that the director received the honour of knighthood.

\section{EDUCATION AT THE BRITISH ASSOCIATION.}

$A$ FTER the presidential address, the section took up $A$ the discussion of the reform of the primary school. Mr. J. C. Legge dealt with handwork, but unfortunately he spent the greater part of his half-hour upon historical and psychological preliminaries. Of the constructive suggestions outlined in the abstract the most interesting was the idea of finding in the soldiers returned from the war a great reservoir of admirable men who might be trained as teachers of handwork. He concluded with a plea for greater freedom to local authorities, a freedom such as would allow them to develop along their own lines, under the gentlest supervision from a very human central authority. Prof. T. P. Nunn pointed out the dangers of formality in handwork - a danger from which $\mathrm{Mr}$. Legge's paper was not wholly free, in so far as it seemed to separate the activity of muscle and nerve from purposefulness. Manual activity must not be regarded as an end in itself, a danger which it shared with all other school subjects, as shown especially by mathematics and geography. Some body of central interest, life itself perhaps, is essential in order to give meaning to the several parts of the curriculum. In school, handwork should be an aid to the so-called intellectual subjects, and it should be the means of developing the feeling for craftsmanship and art. Prof. J. A. Green pleaded for a larger place and a new use for books. The bookiness of the primary school was not due to a superfluity of books, but to the unrealities for which books stood. Rightly understood, it is more books, not fewer, that are wanted there. A disappointing discussion followed, in which side-issues rather than fundamentals were raised-a result perhaps inevitable when the wide range of the subject is remembered.

A better result was achieved next day, when the place of science in secondary and higher education was considered. Mr. J. S. Talbot, referring to a committee of the Incorporated Association of Headmasters which had met recently at Wellington, said there was general agreement as to the necessity of finding a place for science amongst the subjects essential to a good school education. From two and a half to four hours a week should be provided for it in the school time-table of all boys up to sixteen. At the same time, they were not agreed that the school science of to-day was wholly satisfactory. A well-educated boy should surely know something of men like Newton, Darwin, and Pasteur, though he might now do much science at school without hearing of them. Dr. Gray's precise scheme of reform followed broadly the same line. The division between classical and modern sides should, he thought, be dropped for all boys in public schools before sixteen, though the division might take place at fourteen in municipal secondary schools, where it would follow technical and commercial lines of demarcation. After sixteen all boys should be taught the principles of biology. Dr. Hadow dealt with the subject from the point of view of the universities. The present first-year work might be better done in the schools, and the three years' university course begin at the end of what is now the intermediate course. As to research, the pure science student might start immediately he had graduated, but applied science men should go to the works first and return to the university after a year or two there. Dr. E. F. Armstrong deprecated the booky man of science. Present methods produced few men of any use in business where scientific methods of attacking problems were the first essential. But the prizes in industry depended in the last resort upon capacity for organisation and command. In the discussion, all the speakers agreed in condemning early specialisation and demanding a fuller recognition of science in the schools, and some further emphasis was laid upon the doubt as to whether just the right kind of science was being provided for boys amongst whom a large proportion had literary or linguistic tastes. Similar problems in relation to girls' education were discussed in the afternoon, though the issues were narrowed down to the school science more suited to girls preparing for the medical profession on one hand, and for domestic life on the other.

The last meeting of the section was devoted to a consideration of the report of the Mental and Physical Factors Committee, which had conducted an inquiry into the development of facility in the first four rules of arithmetic as shown by elementary-school children between eight and fourteen years of age.

\section{THE BRITISH ASSOCIATION AT NEW CASTLE. SECTION K. BOTANY.}

Opening Address (Abridged) By A. B. Rendle, M.A., D.Sc., F.R.S., President of the Section。

Since our last meeting the Great War has continued to hold chief place in our lives and thoughts, and in various ways, and to a greater or less degree, has influenced our work. In the case of many botany has had for the time being to be set aside, while others have been able to devote only a part of their time to scientific work. On the other hand, it is gratifying to note that some have been able to render helpful service on lines more or less directly connected with their own science. The trained botanist has shown that he may be an eminently adaptable person, capable, after short preparation on special lines, of taking up positions involving scientific investigation of the highest importance from the points of view of medicine and hygiene.

Some months ago the various sectional committees received a request to consider what could be done in their respective sections to meet problems which would arise after the war. Your committee met and discussed the matter, with the result that a set of queries was sent round to representative botanists asking that suggestions might be presented for consideration by the committee. A number of suggestions were received of a very varied kind, indicating that, in the opinion of many botanists at any rate, much might be done to utilise our science and its trained workers in the interests of the State and Empire. Your committee decided to arrange for reports to be prepared on several of the more important aspects by members who were specially fitted to discuss these aspects, and these will be presented in the course of the meeting. These reports will, I am convinced, be of great value, and may lead to helpful discussion; they may also open up the way to useful work.

$$
\text { NO. 2455, VOL. 98] }
$$

